\title{
Rapid detection of multiple class pharmaceuticals in both municipal wastewater and sludge with ultra high performance liquid chromatography tandem mass spectrometry
}

\author{
Xiangjuan Yuan, Zhimin Qiang*, Weiwei Ben, Bing Zhu, Junxin Liu \\ Key Laboratory of Aquatic Science and Technology, Research Center for Eco-Environmental Sciences, Chinese Academy of Sciences, Beijing \\ 100085, China. E-mail: yuanxiangjuan1986@gmail.com
}

\section{A R T I C L E I N F O}

Article history:

Received 29 October 2013

Revised 5 January 2014

Accepted 10 January 2014

Available online 5 July 2014

Keywords:

Pharmaceuticals

Ultrasonic solvent extraction

Solid phase extraction

UPLC-MS/MS

Municipal wastewater

Sludge

\begin{abstract}
A B S T R A C T
This work described the development, optimization and validation of an analytical method for rapid detection of multiple-class pharmaceuticals in both municipal wastewater and sludge samples based on ultrasonic solvent extraction, solid-phase extraction, and ultra high performance liquid chromatography-tandem mass spectrometry quantification. The results indicated that the developed method could effectively extract all the target pharmaceuticals (25) in a single process and analyze them within $24 \mathrm{~min}$. The recoveries of the target pharmaceuticals were in the range of $69 \%-131 \%$ for wastewater and $54 \%-130 \%$ for sludge at different spiked concentration levels. The method quantification limits in wastewater and sludge ranged from 0.02 to $0.73 \mathrm{ng} / \mathrm{L}$ and from 0.02 to $1.00 \mu \mathrm{g} / \mathrm{kg}$, respectively. Subsequently, this method was validated and applied for residual pharmaceutical analysis in a wastewater treatment plant located in Beijing, China. All the target pharmaceuticals were detected in the influent samples with concentrations varying from $0.09 \mathrm{ng} / \mathrm{L}$ (tiamulin) to $15.24 \mu \mathrm{g} / \mathrm{L}$ (caffeine); meanwhile, up to 23 pharmaceuticals were detected in sludge samples with concentrations varying from $60 \mathrm{ng} / \mathrm{kg}$ (sulfamethizole) to $8.55 \mathrm{mg} / \mathrm{kg}$ (ofloxacin). The developed method demonstrated its selectivity, sensitivity, and reliability for detecting multiple-class pharmaceuticals in complex matrices such as municipal wastewater and sludge.

(c) 2014 The Research Center for Eco-Environmental Sciences, Chinese Academy of Sciences.
\end{abstract}

Published by Elsevier B.V.

\section{Introduction}

Pharmaceuticals represent a typical group of emerging contaminants that are widely used as human and veterinary medicine. Antibiotics, anti-inflammatories/analgesics, antiepileptics, steroid compounds, beta-blockers, lipid-regulating agents, and H2-receptor antagonists are the most frequently detected and studied classes of pharmaceuticals (Kasprzyk-Hordern et al., 2008). However, many pharmaceuticals cannot be metabolized completely or eliminated in human and animal bodies, and thus a high percentage may be excreted into the environment as parent compounds, metabolites or conjugates via urine and feces (Kasprzyk-Hordern et al., 2007) The continuous input of these pharmaceuticals has caused their persistence in the environment. So far, various classes of pharmaceuticals have been ubiquitously detected in wastewater, surface water, ground water, and even drinking water (Lindsey et al., 2001; Göbel et al., 2004; Ye et al., 2007; Wang et al., 2011), and in soils, sediments, and biosolids as well (Yang et al., 2010; Chen et al., 2011; Ding et al., 2011).

Because conventional wastewater treatment processes are not specifically designed for the effective removal of pharmaceuticals, the secondary effluent and the sludge of wastewater treatment

*Corresponding author. E-mail: qiangz@rcees.ac.cn (Zhimin Qiang). 
plants (WWTPs) have been proven to be an important pollution source of pharmaceuticals (Nakada et al., 2006; Vieno et al., 2007). Nowadays, serious concerns have been raised regarding the occurrence of pharmaceuticals in the environment due to an increasing reuse of wastewater effluent and excess sludge (e.g., landscape irrigation, crop irrigation, biofertilizer) (Sabourin et al., 2012; Wu et al., 2012). Although the environmental concentrations of the pharmaceuticals are very low, usually at ng/L to $\mu \mathrm{g} / \mathrm{L}$ levels in water phase and $\mathrm{ng} / \mathrm{kg}$ to $\mathrm{mg} / \mathrm{kg}$ levels in solid phase, which are below the toxicity threshold to induce an acute effect, their long-term cumulative impacts on human health and ecosystem safety remain largely unknown (López-Serna et al., 2011). To clarify the behavior, transport and fate of pharmaceuticals in the WWTPs and further assess their potential risks to the environment, it is necessary to develop reliable and versatile analytical methods for rapid detection of multiple-class pharmaceuticals in both wastewater and sludge.

Ultra high performance liquid chromatography in combination with tandem mass spectrometry (UPLC-MS/MS) has been commonly used to analyze pharmaceuticals at trace concentration levels in various environmental samples in the past few years (US EPA, 2007; Gracia-Lor et al., 2011; López-Serna et al., 2011). Meanwhile, ultrasonic solvent extraction (USE) and solid phase extraction (SPE), because of their simple, fast and inexpensive operational merits, have been adopted extensively as pretreatment techniques to extract and enrich micropollutants from various matrices (Lindberg et al., 2005; Pan et al., 2011a). The analysis of pharmaceuticals in the WWTPs represents a difficult task due to the high complexity of the wastewater and sludge matrices. The primary challenge lies in how to improve significantly the extraction and quantification efficiencies because multiple-class pharmaceuticals cover a wide range of $\mathrm{pK}_{\mathrm{a}}$ and $\log \mathrm{K}_{\mathrm{ow}}$ values, polarities, and stabilities that are largely $\mathrm{pH}$ dependent (Batt et al., 2008).

The aim of the present work was to develop a selective, sensitive and reliable analytical method, based on USE/SPE pretreatment and UPLC-MS/MS quantification, for fast detection of multiple-class pharmaceuticals in both municipal wastewater and sludge. The selected pharmaceuticals include sulfonamides, fluoroquinolones, tetracyclines, macrolides, trimethoprim, beta-blockers, antiepileptics, lipid regulators, and stimulants. In comparison to other UPLCMS/MS methods previously published for pharmaceuticals analysis (Xu et al., 2007; Wu et al., 2008; Lillenberg et al., 2009; Ding et al., 2011), the present method has made significant improvements such as an increased number of pharmaceuticals monitored (25), high chromatographic separation efficiency, low detection limits, and reliable quantification by use of four isotopically-labeled internal standards. This method was validated and then successfully applied for residual pharmaceutical analysis in real wastewater and sludge samples collected from the WWTP located in Beijing, China.

\section{Materials and methods}

\subsection{Standards and reagents}

The standards of sulfadiazine (SDZ), sulfathiazole (STZ), sulfamerazine (SMR), sulfamethizole (SML), sulfamethoxazole (SMX), sulfisoxazole (SFX), sulfamethazine (SMN), sulfadimethoxine (SDM), trimethoprim (TMP), ofloxacin (OLF), norfloxacin (NOR), ciprofloxacin (CIP), metoprolol (MET), propranolol (PROP), carbamazepine (CBZ), erythromycin (ERY), clarithromycin (CLA), roxithromycin (ROX), bezafibrate (BF), and atenolol (ATE) were obtained from Sigma-Aldrich (St. Louis, MO, USA). Oxytetracycline (OTC), chlortetracycline (CTC), tetracycline (TCN), demeclocycline (DMC), tiamulin (TIA), and caffeine (CAF) were provided by Dr. Ehrenstorfer $\mathrm{GmbH}$ (Augsburg, Germany). Sulfadimidine $-{ }^{13} \mathrm{C}_{6}$ hemihydrate $\left(\mathrm{SMN}-{ }^{13} \mathrm{C}_{6}\right)$ and ofloxacin $-\mathrm{D}_{3}$ $\left(\mathrm{OLF}-\mathrm{D}_{3}\right)$ were purchased from Witega (Berlin, Germany) and caffeine $-{ }^{13} \mathrm{C}_{3}\left(\mathrm{CAF}-{ }^{13} \mathrm{C}_{3}\right.$ ) from Cerilliant (Round Rock, TX, USA), which were used as internal standards. All the pharmaceutical standards were of the highest purity available ( $\geq 98 \%)$, whose major physicochemical properties were summarized in Appendix A Table S1.

HPLC-grade ultrapure water was produced by passing distilled water through a Milli-Q water purification system (Advantage A10, Millipore, Billerica, MA, USA). HPLC-grade methanol $(\mathrm{MeOH})$, acetonitrile $(\mathrm{ACN})$, dichloromethane, and acetone were purchased from Fisher Scientific (Geel, Belgium), and formic acid (HPLC grade, >99\%) from Dikma Technologies, Inc. (Lake Forest, CA, USA). Analytical grade disodium ethylenediamine tetraacetate ( $\left.\mathrm{Na}_{2} \mathrm{EDTA}\right)$, citric acid monohydrate, $\mathrm{Na}_{2} \mathrm{HPO}_{4}, \mathrm{H}_{2} \mathrm{SO}_{4}, \mathrm{HCl}$, and $\mathrm{NaOH}$ were supplied by Beijing Chemical Reagents Company (Beijing, China). McIlvaine buffer solution was prepared by dissolving $21.00 \mathrm{~g}$ of citric acid monohydrate, $17.75 \mathrm{~g}$ of $\mathrm{Na}_{2} \mathrm{HPO}_{4}$, and $60.50 \mathrm{~g}$ of $\mathrm{Na}_{2}$ EDTA $2 \mathrm{H}_{2} \mathrm{O}$ in $1.625 \mathrm{~L}$ of Milli-Q water, with $\mathrm{pH}$ adjusted to 4.00 using NaOH solution (Pan et al., 2011b).

The individual stock solutions of target pharmaceuticals $(100 \mathrm{mg} / \mathrm{L})$ and internal standards $(1000 \mathrm{mg} / \mathrm{L})$ were prepared in methanol, with the exception of fluoroquinolones (NOR, CIP, OFL, and OLF- $\mathrm{D}_{3}$ ) that were prepared in methanol with $0.2 \%$ (V/V) $1.0 \mathrm{~mol} / \mathrm{L} \mathrm{NaOH}$ added to enhance dissolution. Anhydroerythromycin (ERY- $\left.\mathrm{H}_{2} \mathrm{O}\right)$, a major degradation byproduct of ERY, was prepared according to the method described by McArdell et al. (2003). Being stored in amber glass bottles at $-20^{\circ} \mathrm{C}$, all the stock solutions could keep stable for at least 3 months.

\subsection{Sample pretreatment}

Municipal wastewater and sludge samples were collected from the WWTP using pre-cleaned $1 \mathrm{~L}$ amber glass bottles. After transport to the laboratory, wastewater samples were centrifuged at $7000 \mathrm{r} / \mathrm{min}$ (J2-HS, Beckman Coulter, Brea, CA, USA) for $15 \mathrm{~min}$, and the supernatant was vacuum-filtered through glass microfiber filters (GF/F, Whatman, Maidstone, $\mathrm{UK})$. Thereafter, the supernatant $(200 \mathrm{~mL})$ were acidified to pH 2.5-3.0 by adding $40 \%(\mathrm{~V} / \mathrm{V}) \mathrm{H}_{2} \mathrm{SO}_{4}$ solution, followed by addition of $0.1 \mathrm{~g} \mathrm{Na}_{2}$ EDTA to complex potential interfering metals and improve the extraction efficiency of target analytes (Gros et al., 2009). After pretreatment, the wastewater samples were then kept in the dark at $4^{\circ} \mathrm{C}$ and extracted by SPE within $24 \mathrm{hr}$. Meanwhile, the sludge samples were also centrifuged at $7000 \mathrm{r} / \mathrm{min}$ for $15 \mathrm{~min}$. The suspended solids (SS) at the bottom of centrifuge tubes were carefully collected, freeze-dried under vacuum (FD-1-50, Boyikang, Beijing, China) for at least $48 \mathrm{hr}$, homogenized using a mortar and pestle, sieved to obtain particles with desired diameters $(\leq 0.5 \mathrm{~mm})$, and then stored in amber glass bottles at $-20^{\circ} \mathrm{C}$.

\subsection{Sample extraction}

\subsubsection{Wastewater samples}

The target pharmaceuticals in wastewater samples were extracted by SPE using Oasis HLB cartridges $(6 \mathrm{~mL}, 500 \mathrm{mg}$, Waters, Milford, MA, USA). The cartridges were preconditioned 
sequentially with $5.0 \mathrm{~mL}$ of $\mathrm{MeOH}, 5.0 \mathrm{~mL}$ of $0.5 \mathrm{~mol} / \mathrm{L} \mathrm{HCl}$, and $5.0 \mathrm{~mL}$ of Milli-Q water. Each sample $(200 \mathrm{~mL})$ was spiked with a mixture of four internal standards (100 ng SMN $-{ }^{13} \mathrm{C}_{6}$ for SAs, $100 \mathrm{ng}$ OLF-D $\mathrm{D}_{3}$ for FQs, $100 \mathrm{ng}$ DMC for TCs, and $100 \mathrm{ng} \mathrm{CAF}-{ }^{13} \mathrm{C}_{3}$ for other pharmaceuticals), and then passed through the cartridge at a flow rate of $3 \mathrm{~mL} / \mathrm{min}$. Afterwards, the HLB cartridge was rinsed sequentially with $5 \mathrm{~mL}$ of $5 \%$ methanol aqueous solution and $5 \mathrm{~mL}$ of Milli-Q water, and dried under vacuum. Each cartridge was eluted with $10 \mathrm{~mL}$ of a test eluent. The eluate was collected in a $10 \mathrm{~mL}$ glass vial, dried under a gentle stream of $\mathrm{N}_{2}$, and then dissolved with a mixture of $400 \mu \mathrm{L}$ of $\mathrm{MeOH}$ and $600 \mu \mathrm{L}$ of Milli-Q water. The resulting extract was centrifuged at 10,000 r/min for $6 \mathrm{~min}$ (Centrifuge 5418, Eppendorf, Hamburg, Germany), and the supernatant was separated and filtered through $0.2 \mu \mathrm{m}$ PES filters (PALL, Port Washington, NY, USA) for UPLC-MS/MS analysis.

\subsubsection{Sludge samples}

A $0.5 \mathrm{~g}$ aliquot of the freeze-dried SS sample was accurately weighed into a $30 \mathrm{~mL}$ glass centrifuge tube and spiked with a mixture of four internal standards (100 ng SMN $-{ }^{13} \mathrm{C}_{6}$ for SAs, $500 \mathrm{ng}$ OLF- $\mathrm{D}_{3}$ for FQs, $500 \mathrm{ng}$ DMC for TCs, and $100 \mathrm{ng} \mathrm{CAF}-{ }^{13} \mathrm{C}_{3}$ for other pharmaceuticals). The sludge sample was then vibrated intensively to enable a sufficient contact of the spiked ISs with the matrix. A test extraction solvent $(10 \mathrm{~mL})$ was added to the tube, vortexed for $30 \mathrm{sec}$, ultrasonicated for $10 \mathrm{~min}$, and centrifuged at $5000 \mathrm{r} / \mathrm{min}$ for another $10 \mathrm{~min}$. The sample was extracted three times, and the extracts were combined together and diluted to $300 \mathrm{~mL}$ with Milli-Q water, so that the organic solvent content was reduced to below $5 \%$. Subsequently, the resulting solution was purified and enriched by SPE using the same procedures as for the wastewater samples above.

\subsection{UPLC-MS/MS analysis}

The chromatographic separation of target pharmaceuticals was performed on an Agilent 1290 UPLC system (Wilmington, DE, USA) equipped with an Agilent Zorbax SB-C18 column (100 $\mathrm{mm} \times 2.1 \mathrm{~mm}, 1.8 \mu \mathrm{m})$. The column was maintained at $30^{\circ} \mathrm{C}$ and the injection volume was $5 \mu \mathrm{L}$. Milli-Q water containing $0.2 \%$ formic acid (V/V) (A) and ACN (B) were used as the mobile phases at a flow rate of $0.3 \mathrm{~mL} / \mathrm{min}$. The gradient elution program (time in min, \% mobile phase B) was set as follows: (0, $5),(2,5),(5,13),(8,15),(13,20),(18,30),(25,60),(27,100),(30,100)$, $(30.1,5)$, and $(33,5)$.

An Agilent 6420 Triple Quad LC/MS (Wilmington, DE, USA), equipped with an electrospray ionization source and operated in the positive ion mode, was employed to analyze the target pharmaceuticals. The MS system was operated under the following conditions: capillary voltage $4.0 \mathrm{kV}$, drying gas temperature $300^{\circ} \mathrm{C}$, drying gas flow rate $12 \mathrm{~L} / \mathrm{min}$, and nebulizing gas pressure $276 \mathrm{kPa}$. For each compound, the fragmentor voltage, collision energy (CE), and multiple reaction monitoring mode (MRM) transitions were optimized. Data were acquired under time-segmented conditions based on the chromatographic separation of target pharmaceuticals so as to maximize the detection sensitivity. The MassHunter Workstation Software (B.04.00, Agilent, Wilmington, DE, USA) was employed for both instrument control and data acquisition/analysis.

\subsection{Quantification and method performance}

The target pharmaceuticals were quantified by the internal standard method. Calibration curves were established with mixed pharmaceutical standards and internal standards prepared in Milli-Q water. For each pharmaceutical, its recovery was calculated as the detected concentration of a spiked sample minus that of a non-spiked sample in comparison to the initial spiked concentration. Four mixed internal standards were spiked into the sample prior to the entire analytical procedure, so as to compensate for the loss of target analytes and minimize the matrix effects during sample pretreatment and detection processes. Recoveries were determined by triplicate samples at each concentration level, and the precisions were assessed by the relative standard deviation (RSD). The inter-day precisions for sludge samples were determined by repeating the recovery experiments once a week with triplicate samples for three continuous weeks. Regarding sensitivity, the method detection limit (MDL) and method quantification limit (MQL) were determined for both wastewater and sludge samples using a signal-to-noise $(\mathrm{S} / \mathrm{N})$ ratio approach. The MDL and MQL represented the minimum detection and quantification concentrations that gave $\mathrm{S} / \mathrm{N}$ ratios of 3 and 10 , respectively.

The percent matrix effect (ME, \%) for each pharmaceutical was determined experimentally according to the following equation (Pan et al., 2011a):

$\mathrm{ME}=\frac{\text { Signal response of the spiked post-extracted reference matrix sample }}{\text { Signal response of the spiked Milli-Q water sample }} \times 100 \%$.

It is seen that $100 \%$ of $\mathrm{ME}$ means no matrix interference with the signal of a target analyte; otherwise, an ME value of $>100 \%$ denotes signal enhancement, while a value of $<100 \%$ denotes signal suppression.

\section{Results and discussion}

\subsection{UPLC-MS/MS optimization}

The MS parameters and the MRM transitions for each compound were optimized to achieve the maximum detection sensitivity. All the target pharmaceuticals and internal standards were sensitive in the positive ionization mode. Two MRM transitions between the precursor ion and the two most abundant product ions were monitored for each compound: the first was used for quantification purpose (i.e., quantification transition), whereas the second was used to confirm the presence of the target compound in the sample (confirmation transition). Only one transition was monitored for the isotopically-labeled internal standards. The selected MRM transitions, together with the optimized CE values, fragmentor voltage, and segment period for each compound, are summarized in Table 1.

A sufficient chromatographic separation was important for the high sensitivity and low signal suppression of MS/MS detection. Consequently, a series of preliminary experiments were conducted to optimize the chromatographic separation using a standard mixture of all analytes (100 $\mu \mathrm{g} / \mathrm{L}$ each). Chromatographic separation was carried out in a reversed 
phase with an aqueous ACN mobile phase. The addition of $0.2 \%$ formic acid in the aqueous mobile phase could notably improve the signal sensitivity and peak shape for all analytes. A column temperature of $30^{\circ} \mathrm{C}$ and a flow rate of $0.3 \mathrm{~mL} / \mathrm{min}$ were optimal for pharmaceutical separation. Further increasing the column temperature and flow rate would significantly shift the retention time and lead to insufficient chromatographic separation. The gradient elution programs were optimized to elute all analytes in a reasonably short time (i.e., $24 \mathrm{~min}$ ).

As a result, the operational parameters that provided the highest resolution and the strongest signal response were selected as the optimal conditions for each compound (see Section 1.4). Under the optimized conditions, most of the analytes were well separated within $24 \mathrm{~min}$ and the highest ionization efficiency was achieved, except for a few analytes that were co-eluted, but could be resolved with different ion pairs by MS detection. A representative chromatogram is shown in Appendix A Fig. S1.

\subsection{Analysis of wastewater samples}

\subsubsection{Eluent optimization}

The greatest challenge in multiple-class pharmaceutical analysis concerns the choice of an effective SPE adsorbent and a suitable eluent, which will give an acceptable recovery for all target compounds with diversified physicochemical properties and in complex matrices. Most published methods have confirmed that the Oasis HLB cartridge is the most effective adsorbent with a robust recovery and good reproducibility for the analysis of various therapeutic pharmaceuticals in environmental matrices (Lindsey et al., 2001; Göbel et al., 2004; Ye et al., 2007; Chen et al., 2011); this arises from its chemical composition, which contains both lipophilic divinylbenzene units and hydrophilic $\mathrm{N}$-vinylpyrrolidone units. Therefore, in this study, the Oasis HLB cartridge was also adopted for the extraction of multiple-class pharmaceuticals from aqueous samples.

In the majority of studies, the cartridge eluents are diverse and usually involve various organic solvents, such as methanol, acidified methanol, or ACN based on the physicochemical properties and polarities of target analytes (Seifrtová et al., 2009). In this study, several eluents including (A) ACN; (B) a mixture of dichloromethane and acetone (3:2, V/V); (C) a mixture of $\mathrm{MeOH}$, dichloromethane and acetone (40:36:24, $\mathrm{V} / \mathrm{V} / \mathrm{V}$ ); (D) $\mathrm{MeOH}$; and (E) $\mathrm{MeOH}$ with $0.1 \%$ formic acid were tested to examine the elution efficiencies as expressed by the recoveries of target pharmaceuticals (Fig. 1). The results indicated that eluent A had only a low elution efficiency, especially for TMP, NOR, CIP, TIA, ATE, PROP, and BF, with their recoveries being less than $20 \%$. With an increase in the eluent polarity (i.e., eluent $B<$ eluent $C<$ eluent $D$ ), the overall elution efficiency was gradually improved. For sulfonamides, tetracyclines, TMP, CAF, CBZ, and BF, most of their recoveries were over $70 \%$ and kept relatively stable for the tested eluents (except eluent A). Eluents D and E

Table 1 - Optimal MS/MS parameters for target pharmaceuticals under MRM positive ionization mode.

\begin{tabular}{|c|c|c|c|c|}
\hline Compounds & $\begin{array}{l}\text { Precursor ion } \\
(\mathrm{m} / \mathrm{z})\end{array}$ & $\begin{array}{c}\text { Product ions } \\
(\mathrm{m} / \mathrm{z}) \text { (optimal CE, eV) }\end{array}$ & Fragmentor (V) & $\begin{array}{l}\text { Segment period } \\
\text { (min) }\end{array}$ \\
\hline Atenolol (ATE) & 267.3 & 145.0 (28); $74.1(30)$ & 100 & $0-5.5$ \\
\hline Sulfadiazine (SDZ) & 251.2 & 156.0 (12); $92.1(25)$ & 105 & $0-5.5$ \\
\hline Sulfathiazole (STZ) & 256.3 & 92.1 (25); 156.1 (10) & 100 & $5.5-7.2$ \\
\hline Sulfamerazine (SMR) & 265.3 & $92(40) ; 156(15)$ & 110 & $5.5-7.2$ \\
\hline Caffeine (CAF) & 195.1 & 138.0 (20); 110.1 (30) & 110 & $5.5-7.2$ \\
\hline Caffeine $-{ }^{13} \mathrm{C}_{3}\left(\mathrm{CAF}-{ }^{13} \mathrm{C}_{3}\right)$ & 198.1 & $140.0(20)$ & 105 & $5.5-7.2$ \\
\hline Trimethoprim (TMP) & 291.3 & $230.1(20) ; 123.1(40)$ & 135 & $7.2-10.5$ \\
\hline Sulfamethazine (SMN) & 279.3 & 186 (10); $92(35)$ & 115 & $7.2-10.5$ \\
\hline Sulfadimidine $-{ }^{13} \mathrm{C}_{6}$ hemihydrate $\left(\mathrm{SMN}-{ }^{13} \mathrm{C}_{6}\right)$ & 285.1 & $186.1(15)$ & 105 & $7.2-10.5$ \\
\hline Oxytetracycline (OTC) & 461.3 & 426.2 (15); $442.9(10)$ & 135 & $7.2-10.5$ \\
\hline Sulfamethizole (SML) & 271.3 & 155.9 (10); $92.2(30)$ & 100 & $7.2-10.5$ \\
\hline Ofloxacin (OLF) & 362.3 & 318 (20); $261.2(35)$ & 135 & $7.2-10.5$ \\
\hline Norfloxacin (NOR) & 320.2 & 233.1 (30); 275.9 (15) & 135 & $7.2-10.5$ \\
\hline Ofloxacin- $\mathrm{D}_{3}\left(\mathrm{OLF}-\mathrm{D}_{3}\right)$ & 365.2 & 321.1 (15); 261.1 (30) & 120 & $7.2-10.5$ \\
\hline Ciprofloxacin (CIP) & 332.2 & 288.1 (15); 188.9 (30) & 135 & $7.2-10.5$ \\
\hline Tetracycline (TCN) & 445.3 & 410.2 (15); 154 (25) & 120 & $7.2-10.5$ \\
\hline Metoprolol (MET) & 268.3 & $56.2(35) ; 116.1(25)$ & 115 & $10.5-13$ \\
\hline demeclocycline (DMC) & 465.1 & $154.4(28)$ & 125 & $10.5-13$ \\
\hline Sulfamethoxazole (SMX) & 254.3 & 91.9 (25); $156.0(15)$ & 105 & $10.5-13$ \\
\hline Sulfisoxazole (SFX) & 268.3 & $156.1(10) ; 91.9(30)$ & 105 & 13-16 \\
\hline Chlortetracycline (CTC) & 479.2 & 154 (20); $444(10)$ & 130 & $13-16$ \\
\hline Sulfadimethoxine (SDM) & 311.0 & $92(30) ; 156(20)$ & 110 & $16-19$ \\
\hline Propranolol (PROP) & 260.3 & $116.2(18) ; 74.2(25)$ & 105 & $16-19$ \\
\hline Carbamazepine (CBZ) & 237.2 & 194.2 (20); $179.0(35)$ & 110 & $19-21$ \\
\hline Anhydro-erythromycin (ERY- $\left.\mathrm{H}_{2} \mathrm{O}\right)$ & 716.4 & $558.2(15) ; 158(35)$ & 160 & $21-25$ \\
\hline Tiamulin (TIA) & 494.4 & $192.2(15) ; 119.1(35)$ & 145 & $21-25$ \\
\hline Clarithromycin (CLA) & 748.6 & 158.2 (35); 590.2 (15) & 165 & $21-25$ \\
\hline Roxithromycin (ROX) & 837.6 & $679.3(12) ; 158.2(30)$ & 160 & $21-25$ \\
\hline Bezafibrate (BF) & 362.2 & 316.2 (10); $139.1(30)$ & 110 & $21-25$ \\
\hline
\end{tabular}


showed quite similar elution efficiencies because of their similar polarities. In regard to macrolides and beta-blockers (i.e., ATE, MET, and PROP), eluent D exhibited relatively higher recoveries (53\%-101\%) than eluent E (32\%-83\%). Considering the overall elution performance, $\mathrm{MeOH}$ was selected as the optimal eluent with the mean recoveries of all target pharmaceuticals ranging from $53 \%$ to $132 \%$.

\subsubsection{Method validation for wastewater samples}

Mixed standards of all target pharmaceuticals (including the internal standards) were spiked into Milli-Q water, WWTP influent, and WWTP effluent samples to determine the recovery and precision (RSD) of the developed method. The results indicated that the extraction recoveries and precisions of the target pharmaceuticals ranged from $53 \%$ to $131 \%$ and from $0 \%$ to $13 \%$ for the reference matrices, respectively (Table 2). It is notable that some polar compounds, such as ATE, TIA, NOR, and CIP, achieved higher SPE recoveries as the matrix became more complex, which could arise from the co-elution effect of these compounds with environmental matrices. The US EPA recommends that an analytical method be considered precise when its recoveries are in the range of 70\%-120\% and its RSD values are no more than $20 \%$ for target analytes. Concerning the present method, although a few pharmaceuticals had a recovery out of this specified range, they could still be determined reliably because of their good sensitivity and reproducibility (RSD < 10\%).
As shown in Table 2, a good linearity was achieved for the calibration curves of target pharmaceuticals, with all correlation coefficients $\left(r^{2}\right)$ above 0.99 . Meanwhile, the ME values of all target pharmaceuticals ranged from $87 \%$ to $118 \%$, which denotes that there was no obvious matrix interference to enhance or suppress the analytes' signals after the SPE. The MDLs for the target pharmaceuticals ranged from 0.01 to $0.50 \mathrm{ng} / \mathrm{L}$ in Milli-Q water and from 0.01 to $0.46 \mathrm{ng} / \mathrm{L}$ in wastewater, much lower than those reported previously (Kasprzyk-Hordern et al., 2007, 2008; Li et al., 2009; Gracia-Lor et al., 2011). The results showed that in wastewater macrolides had the lowest MQL (0.02-0.07 ng/L), while CAF had the highest MQL $(0.73 \mathrm{ng} / \mathrm{L})$. The low MQL values make the developed method sensitive enough for the detection of target pharmaceuticals in aqueous environmental samples.

\subsection{Analysis of sludge samples}

\subsubsection{Extraction solvent optimization}

USE has been extensively used for the extraction of inorganic and organic compounds from solid matrices due to its short extraction time, low solvent consumption, and convenient operation. A weakly acidic buffer (e.g., Mcllvaine, citric acid, or phosphate buffer), accompanied with organic solvents, has often been applied to extract antibiotics from animal tissues, soils, sediments, and other solid environmental matrices (Shao et al., 2007; Yang et al., 2010; Chen et al., 2011). The
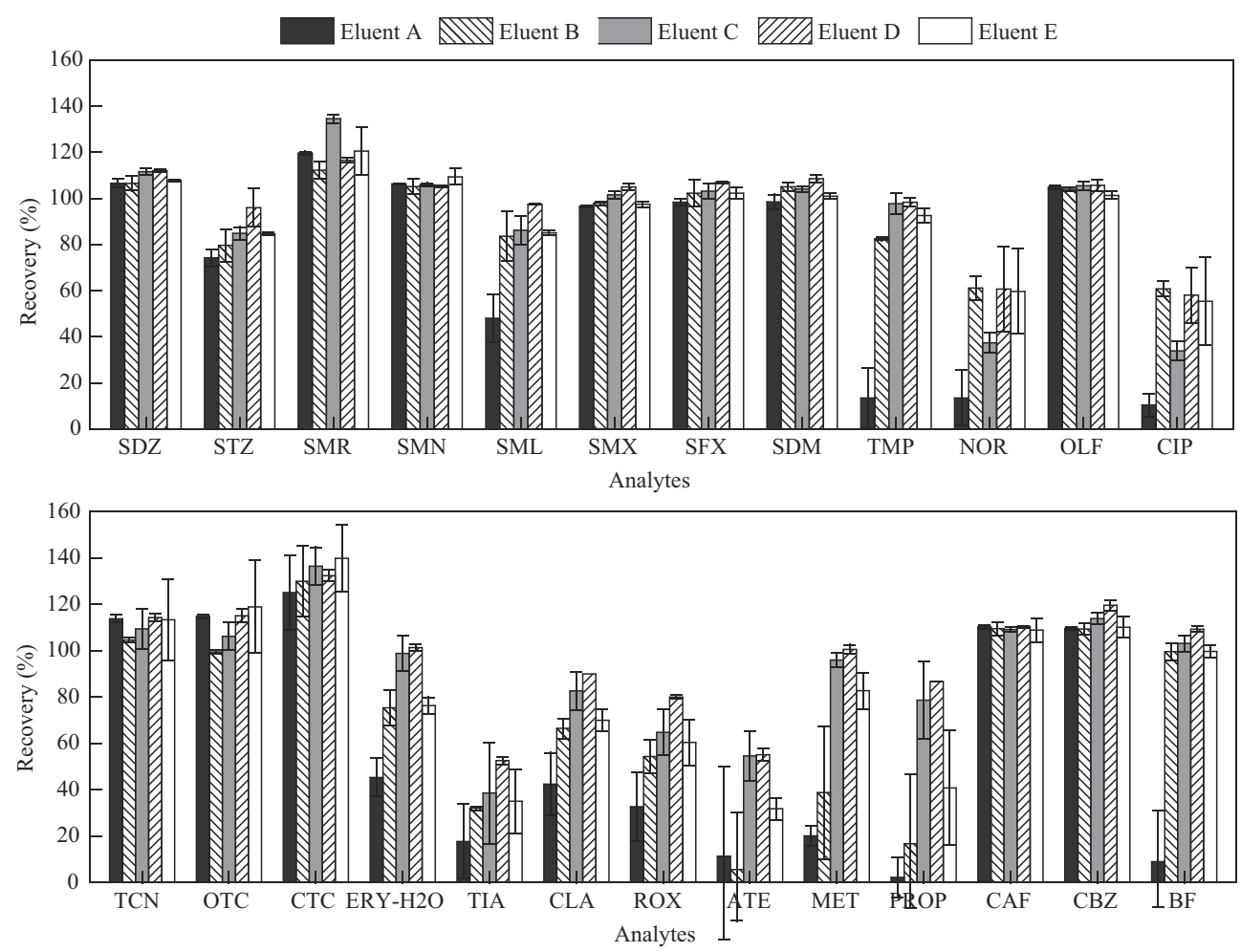

Fig. 1 - Recoveries of target pharmaceuticals with various eluents in Milli-Q water. Eluent A: ACN; eluent B: a mixture of dichloromethane and acetone (3:2, V/V); eluent C: a mixture of $\mathrm{MeOH}$, dichloromethane and acetone (40:36:24, V/V/V); eluent D: $\mathrm{MeOH}$; and eluent E: $\mathrm{MeOH}$ with $\mathbf{0 . 1 \%}$ formic acid. Spiked concentration: $0.5 \mu \mathrm{g} / \mathrm{L}$ for each pharmaceutical and internal standards (triplicate experiments). ACN: acetonitrile; MeOH: methanol. 
Table 2 - Performance and validation of the developed method for wastewater samples $(n=3)$.

\begin{tabular}{|c|c|c|c|c|c|c|c|c|c|}
\hline \multirow[t]{2}{*}{ Compounds } & \multicolumn{3}{|c|}{ Recovery (RSD) (\%) ${ }^{a}$} & \multirow[t]{2}{*}{ Linearity $\left(r^{2}\right)^{c}$} & \multirow[t]{2}{*}{$\operatorname{ME}(\%)$} & \multicolumn{2}{|c|}{ Milli-Q water } & \multicolumn{2}{|c|}{ Wastewater } \\
\hline & Milli-Q Water & WWTP influent & WWTP effluent & & & $\begin{array}{c}\text { MDL } \\
\text { (ng/L) }\end{array}$ & $\begin{array}{c}\text { MQL } \\
\text { (ng/L) }\end{array}$ & $\begin{array}{c}\text { MDL } \\
\text { (ng/L) }\end{array}$ & $\begin{array}{c}\text { MQL } \\
\text { (ng/L) }\end{array}$ \\
\hline SDZ & $108(5)$ & $97(9)$ & 87 (8) & 0.999 & 108 & 0.10 & 0.30 & 0.09 & 0.28 \\
\hline STZ & $93(4)$ & $96(5)$ & $90(4)$ & 0.999 & 118 & 0.10 & 0.25 & 0.08 & 0.21 \\
\hline SMR & 119 (3) & $100(4)$ & $104(5)$ & 0.999 & 117 & 0.10 & 0.25 & 0.09 & 0.21 \\
\hline SMN & $101(6)$ & $110(2)$ & $111(3)$ & 0.999 & 113 & 0.05 & 0.10 & 0.04 & 0.09 \\
\hline SML & $93(7)$ & $106(0)$ & $87(6)$ & 0.999 & 116 & 0.05 & 0.20 & 0.04 & 0.17 \\
\hline SMX & $107(2)$ & $107(13)$ & 91 (11) & 0.999 & 117 & 0.20 & 0.50 & 0.17 & 0.43 \\
\hline SFX & $108(1)$ & $126(4)$ & $97(4)$ & 0.999 & 117 & 0.15 & 0.50 & 0.13 & 0.43 \\
\hline SDM & $106(3)$ & $121(4)$ & $93(4)$ & 0.999 & 118 & 0.10 & 0.30 & 0.08 & 0.25 \\
\hline TMP & $100(2)$ & $72(0)$ & $84(4)$ & 0.993 & 112 & 0.02 & 0.05 & 0.02 & 0.04 \\
\hline NOR & $59(4)$ & $130(3)$ & $131(9)$ & 0.991 & 98 & 0.05 & 0.20 & 0.05 & 0.21 \\
\hline OLF & $103(4)$ & $99(8)$ & $119(2)$ & 0.995 & 107 & 0.01 & 0.03 & 0.01 & 0.02 \\
\hline CIP & $58(0)$ & $112(3)$ & $107(4)$ & 0.998 & 96 & 0.05 & 0.20 & 0.05 & 0.21 \\
\hline TCN & $107(10)$ & $108(1)$ & $97(2)$ & 0.997 & 87 & 0.10 & 0.25 & 0.11 & 0.29 \\
\hline ОTC & $105(9)$ & $120(6)$ & $111(3)$ & 0.996 & 111 & 0.10 & 0.30 & 0.09 & 0.27 \\
\hline CTC & $122(1)$ & $93(5)$ & $91(10)$ & 0.998 & 92 & 0.20 & 0.50 & 0.22 & 0.54 \\
\hline ERY- $\mathrm{H}_{2} \mathrm{O}$ & $100(2)$ & $73(5)$ & $80(2)$ & 0.999 & 115 & 0.02 & 0.08 & 0.02 & 0.07 \\
\hline TIA & $53(2)$ & $81(2)$ & $83(3)$ & 0.999 & 109 & 0.02 & 0.05 & 0.02 & 0.05 \\
\hline CLA & 90 (1) & $73(4)$ & $81(1)$ & 0.999 & 107 & 0.01 & 0.03 & 0.01 & 0.02 \\
\hline ROX & $75(10)$ & $71(7)$ & $79(2)$ & 0.999 & 115 & 0.01 & 0.03 & 0.01 & 0.02 \\
\hline ATE & $55(0)$ & $69(0)$ & $69(3)$ & 0.998 & 108 & 0.10 & 0.30 & 0.09 & 0.28 \\
\hline MET & $99(2)$ & $90(4)$ & 75 (9) & 0.995 & 113 & 0.20 & 0.50 & 0.18 & 0.44 \\
\hline PROP & $87(0)$ & $102(3)$ & $86(5)$ & 0.994 & 113 & 0.10 & 0.30 & 0.09 & 0.26 \\
\hline CAF & $107(5)$ & $107(4)^{b}$ & $110(10)$ & 0.999 & 110 & 0.50 & 0.80 & 0.46 & 0.73 \\
\hline CBZ & $116(5)$ & $91(1)$ & $94(2)$ & 0.996 & 117 & 0.05 & 0.20 & 0.04 & 0.17 \\
\hline $\mathrm{BF}$ & $105(6)$ & $88(3)$ & $88(3)$ & 0.999 & 115 & 0.05 & 0.20 & 0.04 & 0.17 \\
\hline $\begin{array}{l}\text { a Spiked conc } \\
\text { b Spiked conc } \\
\text { c Concentratic }\end{array}$ & $\begin{array}{l}\text { ration: } 0.5 \mu \mathrm{g} / \mathrm{L} \text {. } \\
\text { ration: } 10 \mu \mathrm{g} / \mathrm{L}(\mathrm{b} \\
\text { range for calibra }\end{array}$ & $\begin{array}{l}\text { cause of the high } \\
\text { in curves: } 0.5-300\end{array}$ & $\begin{array}{l}\text { Icentration of CAF } \\
\text { L (each compoun }\end{array}$ & the WWTP inf & & & & & \\
\hline
\end{tabular}

acidification of the extraction solvent protonates the acidic functional groups (e.g., carboxylic acids and phenols) present in the organic fractions of sewage sludge, and thereby reduces the electrostatic interactions between sludge and cationic moieties (Ding et al., 2011). In this study, six different extraction solvents were evaluated for extracting 25 pharmaceuticals simultaneously from sludge samples. The tested solvents included: (A) 1:1 (V/V) mixture of $\mathrm{MeOH}$ and $0.2 \mathrm{~mol} / \mathrm{L}$ citric acid buffer (pH 4.4); (B) 1:1 (V/V) mixture of ACN and $0.2 \mathrm{~mol} / \mathrm{L}$ citric acid buffer ( $\mathrm{pH} 4.4$ ); (C) $0.2 \mathrm{~mol} / \mathrm{L}$ citric acid buffer ( $\mathrm{pH} 4.4$ ); (D) 1:1 (V/V) mixture of MeOH and McIlvaine buffer ( $\mathrm{pH} 4.0)$; (E) 1:1 (V/V) mixture of ACN and McIlvaine buffer ( $\mathrm{pH} 4.0)$; and (F) McIlvaine buffer ( $\mathrm{pH}$ 4.0). The SS samples were extracted using the same procedures as detailed in Section 1.3.2.

The extraction efficiencies of the target analytes, as expressed by the recovery ratios, are given in Fig. 2. The results indicated that among the six extraction solvents tested, relatively higher extraction efficiencies were achieved for the mixtures containing an organic solvent. A single citric acid buffer (solvent $\mathrm{C}$ ) or McIlvaine buffer (solvent F) failed to extract fluoroquinolones (NOR, OLF, and CIP), TCN, OTC, TIA, and PROP from sludge, yielding relatively lower recoveries $(<40 \%)$. Only eluent A showed good extraction efficiency (101\%) for SFX. The fluoroquinolones (NOR, OLF, and CIP) could be extracted effectively by solvent $A$ with recoveries of $65 \%-73 \%$, while their recoveries obtained by solvent D were all below 50\%. Fluoroquinolones and tetracyclines have been proven to sorb strongly to the solid phase via interactions such as hydrogen bonding with organic matter and complexing with metal cations (Wu et al., 2008). Solvent A was more effective in extracting the target pharmaceuticals from sludge than solvent $D$, and the low recoveries (<50\%) for NOR, CIP, OLF, OTC, and TCN by other solvents may be attributed to the matrix effect and/or the insufficient extraction. In brief, solvent $\mathrm{A}$ was the most effective extraction solvent for all target pharmaceuticals, leading to high overall recoveries of $60 \%-118 \%$.

\subsubsection{Method validation for sludge samples}

To examine the recoveries of target pharmaceuticals, three concentration levels of all selected pharmaceuticals and internal standards were fortified in the freeze-dried SS samples, while the same amount of internal standards was only spiked into the blank SS samples. The SS samples were then vibrated intensively to enable a sufficient contact of the spiked compounds with the matrix and kept $2 \mathrm{hr}$ prior to USE and SPE.

As shown in Table 3, the recoveries of all target pharmaceuticals (except ATE) ranged from $61 \%$ to $130 \%$ at the three spiked concentration levels, and the RSD were within the range of $0 \%-11 \%$. The inter-day precisions for sludge samples were determined by repeating the recovery experiments once a week with triplicate samples for three continuous weeks, 

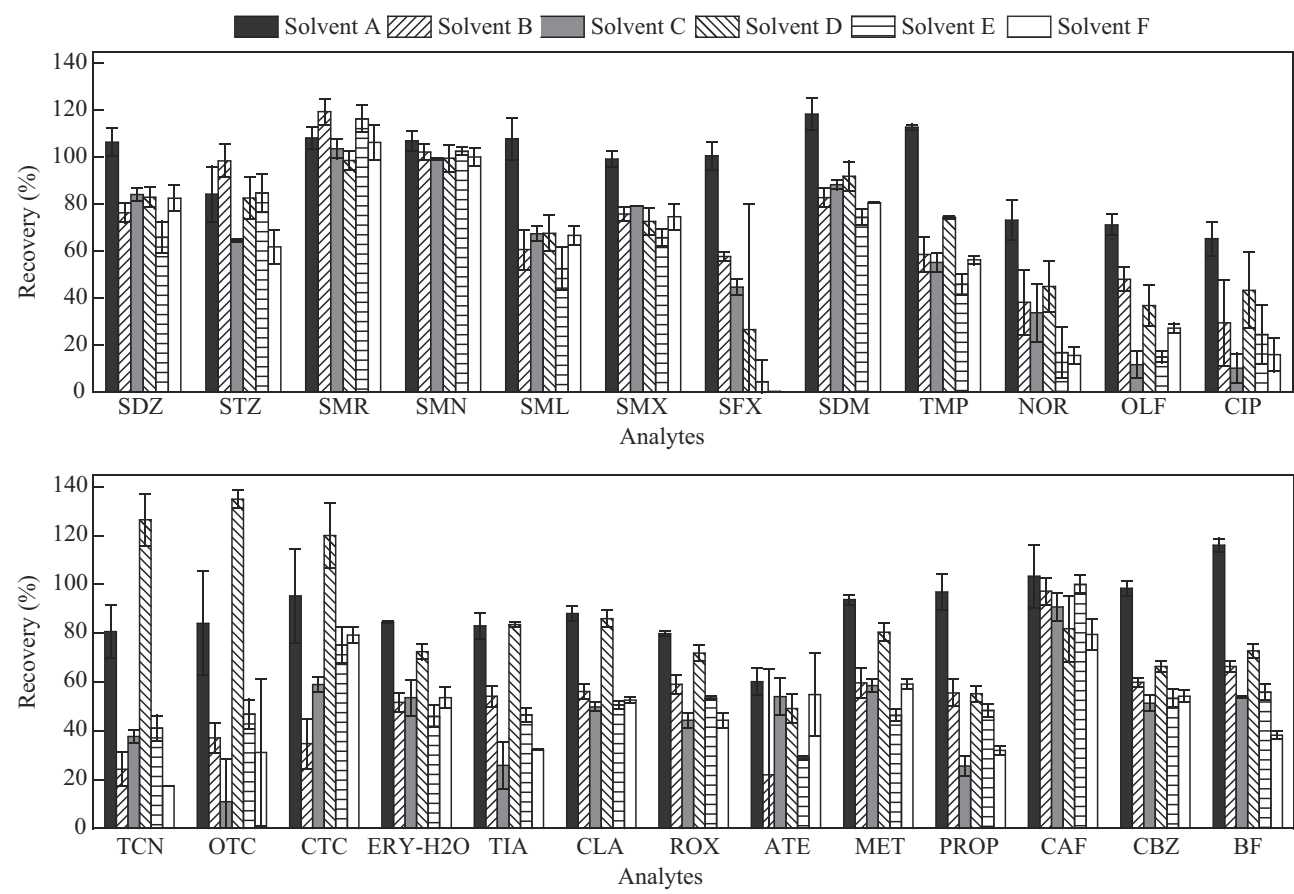

Fig. 2 - The recoveries of target pharmaceuticals with various extraction solvents in sludge phase. Solvent A: 1:1 (V/V) mixture of $\mathrm{MeOH}$ and $0.2 \mathrm{~mol} / \mathrm{L}$ citric acid buffer (pH 4.4); solvent B: 1:1 (V/V) mixture of ACN and $0.2 \mathrm{~mol} / \mathrm{L}$ citric acid buffer (pH 4.4); solvent C: $0.2 \mathrm{~mol} / \mathrm{L}$ citric acid buffer (pH 4.4); solvent D: $1: 1$ (V/V) mixture of MeOH and McIlvaine buffer (pH 4.0); solvent E: 1:1 (V/V) mixture of ACN and Mcllvaine buffer (pH 4.0); and solvent F: Mcllvaine buffer (pH 4.0). Spiked concentrations: sulfonamides and $S M N-{ }^{13} \mathrm{C}_{6} 0.2 \mathrm{mg} / \mathrm{kg}$, tetracyclines and DMC $1.0 \mathrm{mg} / \mathrm{kg}$, fluoroquinolones and OLF- $\mathrm{D}_{3} 1.0 \mathrm{mg} / \mathrm{kg}, \mathrm{macrolides}$ $0.2 \mathrm{mg} / \mathrm{kg}$, other pharmaceuticals and $\mathrm{CAF}-{ }^{13} \mathrm{C}_{3} 0.2 \mathrm{mg} / \mathrm{kg}$ (triplicate experiments).

and the inter-day reproducibility was expressed by the RSD value of repeated analyses. The developed method showed good reproducibility with inter-day precisions being below $13 \%$. Although the ATE exhibited a relatively lower recovery (54\%-58\%) than all other compounds, its good sensitivity, precision and reproducibility (RSD $\leq 11 \%$ ) make the developed method still applicable for the detection of ATE in sludge samples.

The calibration curves of each target compound consisted of nine points and were established with a series of mixed standards (including internal standards) prepared in Milli-Q water within a concentration range of 1-500 $\mu \mathrm{g} / \mathrm{L}$. The correlation coefficients $\left(r^{2} \geq 0.995\right)$ showed a good linearity of the method for all target pharmaceuticals.

The ME values of the target pharmaceuticals ranged from $74 \%$ to $144 \%$ (Table 3 ). The high ME values for NOR, CIP, and ATE (>120\%) indicate that the presence of sludge matrix obviously enhanced the ionization and the signal response. However, SML and ROX were subjected to strong ionization suppression, with ME values of $74 \%$ and $75 \%$, respectively. For other target pharmaceuticals, there was no obvious matrix interference to enhance or suppress the analytes' signal response (ME $=80 \%-120 \%)$.

The MDLs ranged from 0.01 (TMP, TIA, and ROX) to $0.50 \mu \mathrm{g} / \mathrm{kg}$ (CTC), and the MQLs ranged from 0.02 (TMP) to $1.00 \mu \mathrm{g} / \mathrm{kg}$ (SDZ, CTC, and ATE) (Table 3). The MQLs of SDM, SDZ, OLF, CIP, NOR, ROX, and ERY- $\mathrm{H}_{2} \mathrm{O}$ obtained in this work were much lower than those reported by previous studies in sewage sludge (Xu et al., 2007; Lillenberg et al., 2009; Gao et al., 2012). The detection limits and precisions prove that the developed method was sensitive and reliable for monitoring multiple-class pharmaceuticals in sewage sludge.

\subsection{Residual pharmaceuticals detection in a municipal WWTP}

The developed method was applied to determine the concentrations of target pharmaceuticals in municipal wastewater and sludge samples collected from the WWTP. The sampling points along the $\mathrm{A} / \mathrm{A} / \mathrm{O}$ treatment process in this WWTP are illustrated in Appendix A Fig. S2. Triplicate analyses were performed for each sample.

Fig. 3 shows that all target pharmaceuticals were detected in the influent. The most abundant compounds detected were CAF $(15.24 \mu \mathrm{g} / \mathrm{L})$ and OLF $(1.35 \mu \mathrm{g} / \mathrm{L})$, probably because of the large consumption of soft drinks containing CAF (e.g., coffee, tea, and coke) and the extensive usage of antibiotics in China. Meanwhile, NOR (509 ng/L), SMX (398 ng/L), MET (256 ng/L), and ERY- $\mathrm{H}_{2} \mathrm{O}(228 \mathrm{ng} / \mathrm{L})$ also showed relatively high concentrations in the influent. In the secondary effluent, OLF, MET, SMX, and NOR were identified as the predominant pharmaceuticals, with concentrations of $367,194,102$, and $78 \mathrm{ng} / \mathrm{L}$, respectively. Only SFX was below its LOQ, whereas the mean concentrations of other 20 pharmaceuticals ranged from 0.1 to $54.6 \mathrm{ng} / \mathrm{L}$. 
Table 3 - Performance and validation of the developed method for sludge samples $(n=3)$.

\begin{tabular}{|c|c|c|c|c|c|c|c|c|}
\hline \multirow[t]{2}{*}{ Compounds } & \multicolumn{3}{|c|}{ Recovery (RSD) ${ }^{a}(\%)$} & \multirow[t]{2}{*}{ Inter-day precisions ${ }^{\mathrm{b}}(\%)$} & \multirow[t]{2}{*}{ Linearity $\left(r^{2}\right)^{c}$} & \multirow[t]{2}{*}{ ME (\%) } & \multirow[t]{2}{*}{ MDL $(\mu \mathrm{g} / \mathrm{kg})$} & \multirow[t]{2}{*}{ MQL $(\mu g / k g)$} \\
\hline & High level & Middle level & Low level & & & & & \\
\hline SDZ & 95 (3) & $112(0)$ & $100(2)$ & 6 & 0.999 & 94 & 0.40 & 1.00 \\
\hline STZ & $96(1)$ & $130(5)$ & $112(0)$ & 11 & 0.999 & 96 & 0.10 & 0.25 \\
\hline SMR & $103(3)$ & $105(5)$ & $109(0)$ & 4 & 0.999 & 99 & 0.04 & 0.20 \\
\hline SMN & $93(3)$ & $114(2)$ & $102(2)$ & 6 & 0.999 & 105 & 0.02 & 0.05 \\
\hline SML & $62(1)$ & $82(0)$ & $67(4)$ & 7 & 0.999 & 74 & 0.02 & 0.05 \\
\hline SMX & $92(5)$ & $103(2)$ & $107(0)$ & 3 & 0.999 & 89 & 0.15 & 0.40 \\
\hline SFX & $97(3)$ & $115(1)$ & $105(0)$ & 12 & 0.999 & 107 & 0.05 & 0.20 \\
\hline SDM & $110(4)$ & 108 (1) & $120(1)$ & 9 & 0.999 & 115 & 0.02 & 0.05 \\
\hline TMP & $97(8)$ & $89(0)$ & $97(9)$ & 8 & 0.995 & 96 & 0.01 & 0.02 \\
\hline NOR & 74 (11) & $89(7)$ & $74(4)$ & 12 & 0.998 & 124 & 0.10 & 0.20 \\
\hline OLF & 82 (11) & $107(8)$ & $117(3)$ & 7 & 0.999 & 109 & 0.05 & 0.15 \\
\hline CIP & $64(5)$ & $61(2)$ & $63(5)$ & 10 & 0.999 & 144 & 0.10 & 0.20 \\
\hline TCN & $98(2)$ & $100(7)$ & $110(2)$ & 13 & 0.997 & 115 & 0.20 & 0.50 \\
\hline OTC & $76(8)$ & 105 (10) & $65(0)$ & 13 & 0.997 & 99 & 0.15 & 0.80 \\
\hline СТС & $84(1)$ & $82(5)$ & $89(2)$ & 10 & 0.998 & 114 & 0.50 & 1.00 \\
\hline ERY- $\mathrm{H}_{2} \mathrm{O}$ & $76(0)$ & $70(6)$ & $83(9)$ & 9 & 0.999 & 82 & 0.02 & 0.05 \\
\hline TIA & $67(2)$ & $80(3)$ & $67(2)$ & 10 & 0.999 & 85 & 0.01 & 0.03 \\
\hline CLA & $72(0)$ & $82(2)$ & $71(2)$ & 7 & 0.999 & 82 & 0.02 & 0.05 \\
\hline ROX & 77 (2) & $90(3)$ & 79 (3) & 7 & 0.999 & 75 & 0.01 & 0.03 \\
\hline ATE & $54(7)$ & $58(2)$ & $56(3)$ & 11 & 0.999 & 139 & 0.20 & 1.00 \\
\hline MET & 81 (1) & $92(2)$ & 87 (1) & 8 & 0.999 & 105 & 0.04 & 0.15 \\
\hline PROP & $71(3)$ & $81(2)$ & $68(2)$ & 13 & 0.998 & 96 & 0.03 & 0.20 \\
\hline $\mathrm{CAF}$ & $100(5)$ & $115(3)$ & $102(3)$ & 7 & 0.999 & 116 & 0.20 & 0.80 \\
\hline CBZ & $88(5)$ & $86(3)$ & $82(2)$ & 3 & 0.997 & 87 & 0.05 & 0.20 \\
\hline $\mathrm{BF}$ & $90(0)$ & $86(2)$ & $92(1)$ & 6 & 0.999 & 105 & 0.03 & 0.20 \\
\hline
\end{tabular}

a Spiked concentrations:

high level: $1.0 \mathrm{mg} / \mathrm{kg}$ for sulfonamides, $1.0 \mathrm{mg} / \mathrm{kg}$ for macrolides, $10 \mathrm{mg} / \mathrm{kg}$ for tetracyclines, $10 \mathrm{mg} / \mathrm{kg}$ for fluoroquinolones, and $1.0 \mathrm{mg} / \mathrm{kg}$ for other pharmaceuticals;

middle level: $0.2 \mathrm{mg} / \mathrm{kg}$ for sulfonamides, $0.2 \mathrm{mg} / \mathrm{kg}$ for macrolides, $1.0 \mathrm{mg} / \mathrm{kg}$ for tetracyclines, $1.0 \mathrm{mg} / \mathrm{kg}$ for fluoroquinolones, and $0.2 \mathrm{mg} / \mathrm{kg}$ for other pharmaceuticals;

low level: $0.02 \mathrm{mg} / \mathrm{kg}$ for sulfonamides, $0.02 \mathrm{mg} / \mathrm{kg}$ for macrolides, $0.2 \mathrm{mg} / \mathrm{kg}$ for tetracyclines, $0.2 \mathrm{mg} / \mathrm{kg}$ for fluoroquinolones, and $0.02 \mathrm{mg} / \mathrm{kg}$ for other pharmaceuticals.

b Spiked concentrations were the same as the middle level.

c Concentration range for calibration curves: 1-500 $\mu \mathrm{g} / \mathrm{L}$ (each compound).

The distribution patterns of target pharmaceuticals obtained in this study are quite different from those found in other countries. In Korea, the mean influent concentrations of ATE, CBZ, and TMP ranged from 72 to 7810 ng/L (Behera et al., 2011). In the UK, the mean influent concentrations of ATE, CBZ, PROP and BF were 12,913, 1694, 557 and $420 \mathrm{ng} / \mathrm{L}$, respectively (Kasprzyk-Hordern et al., 2009), which are much higher than those measured in this study, i.e., 27, 30, 6 and $61 \mathrm{ng} / \mathrm{L}$, correspondingly (Fig. 3). In addition, similar concentration ranges for SMX and OLF were reported (0.29-1.00 and 0.44-3.10 $\mu \mathrm{g} / \mathrm{L}$, respectively) in the influents of eight WWTPs located in Beijing (Gao et al., 2012). ERY- $\mathrm{H}_{2} \mathrm{O}$ was the most abundant macrolides detected in the influent, whose mean concentrations were reported as $0.63 \mu \mathrm{g} / \mathrm{L}$ in Hong Kong (Gulkowska et al., 2008), and $0.34 \mu \mathrm{g} / \mathrm{L}$ in Spain (Rosal et al., 2010), which are comparable to the result in this study.

Since the physicochemical properties of the target pharmaceuticals are significantly different from each other, their removal efficiencies varied over a wide range from $-67 \%$ to nearly $100 \%$. Among the target pharmaceuticals, above $90 \%$ of STZ, SMR, SDM, CLA, ATE, and CAF were removed by the $\mathrm{A} / \mathrm{A} / \mathrm{O}$ process. $\mathrm{CAF}$ and $\mathrm{TMP}$ proved to be readily biodegradable (Ternes et al., 2001; Thomas and Foster, 2005; Xue et al., 2010). The median removal efficiency of BF was found to be $87 \%$ in six Italian WWTPs (Castiglioni et al., 2006), similar to that observed (83\%) in this study. It is notable that CBZ showed a negative removal efficiency (i.e., $-67 \%$ ), which possibly arose from the transformation of the conjugated forms (e.g., glucuronide conjugate, hydroxylated metabolites) into the free form by microorganisms (Miao et al., 2005; Vieno et al., 2007).

Table 4 presents the concentrations of target pharmaceuticals in various sludge samples (i.e., anaerobic, anoxic, oxic, and return) along the $\mathrm{A} / \mathrm{A} / \mathrm{O}$ treatment process. The results indicated that up to 23 pharmaceuticals were detected, among which fluoroquinolones and tetracyclines were the most predominant classes, with much higher concentrations than those of other compounds. The mean concentrations of fluoroquinolones and tetracyclines ranged from 231 to $8546 \mu \mathrm{g} / \mathrm{kg}$ and from 16 to $7106 \mu \mathrm{g} / \mathrm{kg}$, respectively. The high concentrations of fluoroquinolones and tetracyclines in the sludge samples arose from their continuous input into the raw wastewater and subsequent strong adsorption onto the sludge. Previous studies have demonstrated that fluoroquinolones and 

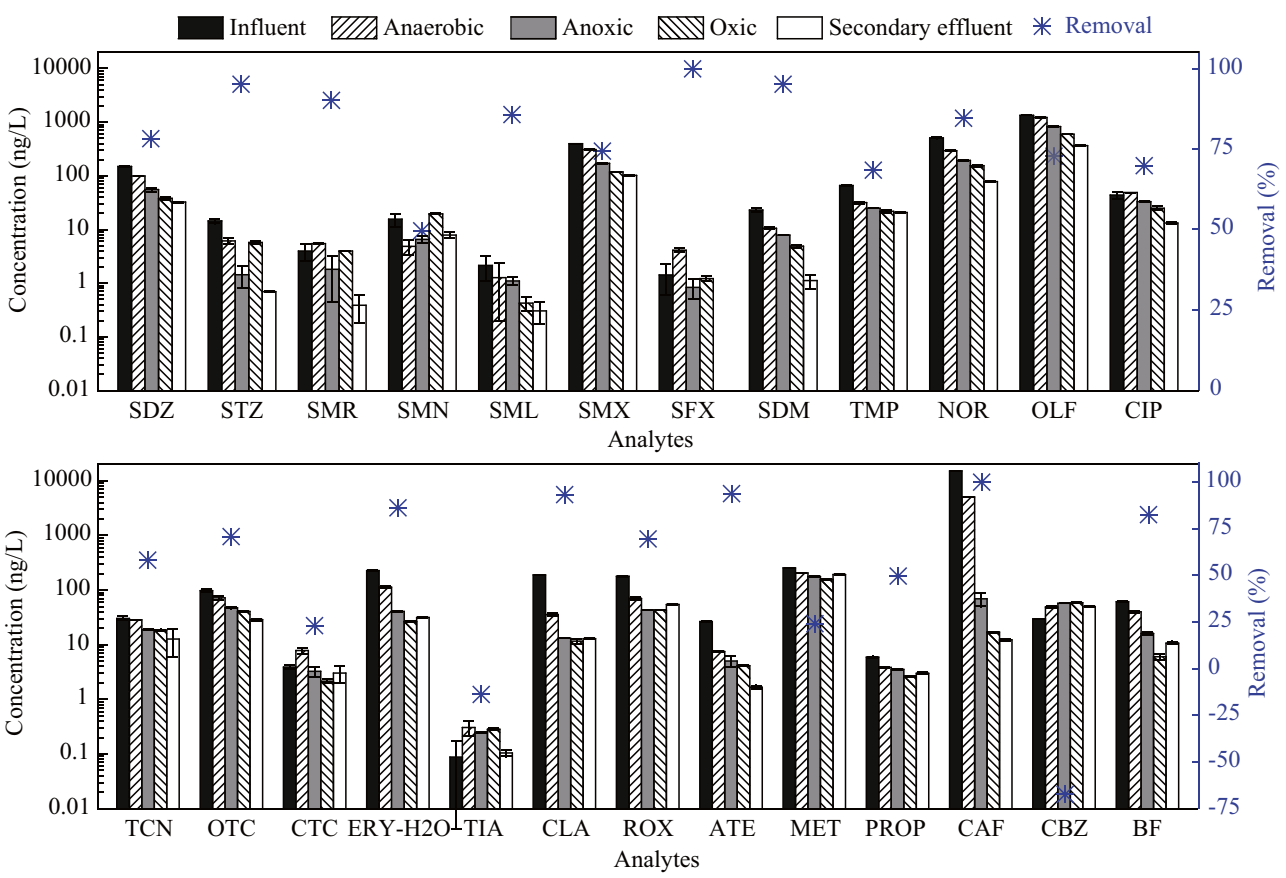

Fig. 3 - Detected concentrations and removal efficiencies of target pharmaceuticals in wastewater samples from various treatment units in the studied WWTP.

tetracyclines could be strongly adsorbed to sludge because of their high solid-water distribution coefficients $\left(K_{d}\right)$, and sludge adsorption was the primary removal pathway for fluoroquinolones and tetracyclines in WWTPs (Okuda et al., 2009; Li and Zhang, 2010; Jia et al., 2012). The concentrations of sulfonamides, macrolides, and other pharmaceuticals in the sludge samples were relatively lower, especially SFX and ATE (<LOQs). SMN, SML, SFX, and TIA are specifically used as veterinary antibiotics to control infections and promote growth of livestock (Ben et al., 2008; Pan et al., 2011b), so it is reasonable that these compounds were present with a very low concentration in municipal wastewater and sludge.

The different distribution patterns of target pharmaceuticals detected in the WWTP could arise from the diversified pharmaceutical usages in various countries (Behera et al., 2011). Our experimental results clearly revealed that the A/A/ $O$ treatment process, which has been extensively adopted in the WWTPs of China, could not completely remove the target pharmaceuticals, and thus a certain amount of pharmaceuticals still remain in the secondary effluent and sludge. Thus, advanced treatment technologies (e.g., membrane filtration, ozonation) are required to remove the residual pharmaceuticals in the WWTP effluents. For the sludge, although both anaerobic digestion and composting methods could achieve partial removal of the pharmaceuticals (Martín et al., 2012; Narumiya et al., 2013), the residues could still remain in soils for a long time (from months to years) because of their strong sorption and low biodegradation (Wilson et al., 1997). Hence, the environmental behaviors and associated ecotoxicological risks of the residual pharmaceuticals in sewage sludge (e.g., release to surface and ground waters through sludge agricultural application) need further investigation.

\section{Conclusions}

A selective, sensitive and reliable method was developed for the rapid detection of sulfonamides, fluoroquinolones, tetracyclines, macrolides, and other pharmaceuticals in both municipal wastewater and sludge. These pharmaceuticals could be extracted effectively from sludge by USE with methanol and $0.2 \mathrm{~mol} / \mathrm{L}$ citric acid (1:1, V/V) as an optimal extraction solvent. The extracts and wastewater were enriched and purified by SPE using the HLB cartridge as absorbent and methanol as eluent. The UPLC-MS/MS optimization results indicated that good separation of 25 pharmaceuticals and 4 internal standards could be achieved within $24 \mathrm{~min}$. Method validation tests showed that the entire method had high and stable recoveries, low MDLs, and insignificant matrix interference for the majority of target pharmaceuticals.

The main advantages of the developed method lie in its synchronous enrichment, effective purification, fast and high separation efficiency, and reliable quantification by use of four isotopically-labeled ISs for target pharmaceuticals analysis. This method was well applicable for detecting multiple-class pharmaceuticals in various wastewater and sludge matrices. By using this method, all the 25 target pharmaceuticals were detected in raw wastewater samples and up to 23 were detected in sludge samples from the WWTP. In addition, it can be readily extended to other types of relatively simpler matrices, such as surface water, ground water, drinking water, sediments, and soils.

\section{Acknowledgments}

This work was supported by the National Natural Science Foundation of China (No. 51138009, 21107127), the Ministry of 


\begin{tabular}{|c|c|c|c|c|}
\hline \multirow[t]{2}{*}{ Compounds } & \multicolumn{4}{|c|}{ Mean concentration (SD) $(n=3)$} \\
\hline & $\begin{array}{l}\text { Anaerobic } \\
\text { sludge }\end{array}$ & $\begin{array}{l}\text { Anoxic } \\
\text { sludge }\end{array}$ & $\begin{array}{c}\text { Oxic } \\
\text { sludge }\end{array}$ & $\begin{array}{l}\text { Return } \\
\text { sludge }\end{array}$ \\
\hline SDZ & $5.32(0.23)$ & $5.93(0.03)$ & $5.90(0.09)$ & $3.74(0.07)$ \\
\hline STZ & $1.79(0.52)$ & $2.51(0.09)$ & $2.79(0.81)$ & $0.97(0.14)$ \\
\hline SMR & $15.51(0.09)$ & $14.85(0.17)$ & $\begin{array}{l}14.65 \\
(0.10)\end{array}$ & $\begin{array}{l}15.30 \\
(0.72)\end{array}$ \\
\hline SMN & $0.38(0.17)$ & $0.41(0.15)$ & $0.38(0.02)$ & $0.43(0.02)$ \\
\hline SML & $0.26(0.02)$ & $0.10(0.03)$ & $0.18(0.02)$ & $0.06(0.00)$ \\
\hline SMX & $14.90(0.35)$ & $13.99(0.02)$ & $\begin{array}{l}15.06 \\
(0.06)\end{array}$ & $\begin{array}{l}10.74 \\
(0.26)\end{array}$ \\
\hline SFX & $<$ LOQ & $<$ LOQ & $<\mathrm{LOQ}$ & $<$ LOQ \\
\hline SDM & $0.58(0.06)$ & $0.54(0.01)$ & $0.81(0.10)$ & $1.02(0.11)$ \\
\hline TMP & $154.91(4.67)$ & $\begin{array}{l}41.89 \\
(11.91)\end{array}$ & $\begin{array}{l}108.71 \\
(14.97)\end{array}$ & $\begin{array}{l}195.97 \\
(3.21)\end{array}$ \\
\hline NOR & $2475.34(1.29)$ & $\begin{array}{l}2796.68 \\
(29.60)\end{array}$ & $\begin{array}{l}2480.60 \\
(115.72)\end{array}$ & $\begin{array}{l}1967.71 \\
(5.28)\end{array}$ \\
\hline OLF & $\begin{array}{l}7962.60 \\
(55.46)\end{array}$ & $\begin{array}{l}8546.21 \\
(49.50)\end{array}$ & $\begin{array}{l}8504.97 \\
(89.92)\end{array}$ & $\begin{array}{l}6029.07 \\
(75.82)\end{array}$ \\
\hline CIP & $316.51(2.17)$ & $\begin{array}{l}355.40 \\
(4.69)\end{array}$ & $\begin{array}{l}322.45 \\
(9.09)\end{array}$ & $\begin{array}{l}230.93 \\
(1.71)\end{array}$ \\
\hline TCN & $4457.02(1.80)$ & $\begin{array}{l}387.66 \\
(14.51)\end{array}$ & $\begin{array}{l}386.64 \\
(6.15)\end{array}$ & $\begin{array}{l}277.93 \\
(5.25)\end{array}$ \\
\hline OTC & $\begin{array}{l}7105.54 \\
(34.15)\end{array}$ & $\begin{array}{l}993.75 \\
(16.22)\end{array}$ & $\begin{array}{l}990.50 \\
(22.42)\end{array}$ & $\begin{array}{l}751.71 \\
(12.30)\end{array}$ \\
\hline CTC & $222.66(0.55)$ & $16.04(5.13)$ & $\begin{array}{l}37.91 \\
(9.29)\end{array}$ & $\begin{array}{l}15.53 \\
(1.49)\end{array}$ \\
\hline $\mathrm{ERY}-\mathrm{H}_{2} \mathrm{O}$ & $4.06(1.08)$ & $9.75(0.04)$ & $6.45(1.79)$ & $3.30(0.01)$ \\
\hline TIA & $0.25(0.03)$ & $0.28(0.01)$ & $0.28(0.01)$ & $0.28(0.03)$ \\
\hline CLA & $8.85(0.11)$ & $28.31(0.17)$ & $7.76(0.01)$ & $7.19(0.17)$ \\
\hline ROX & $13.06(0.25)$ & $23.57(0.31)$ & $\begin{array}{l}12.17 \\
(0.53)\end{array}$ & $\begin{array}{l}11.21 \\
(0.21)\end{array}$ \\
\hline ATE & $<$ LOQ & $<\mathrm{LOQ}$ & $<$ LOQ & $<\mathrm{LOQ}$ \\
\hline MET & $8.47(0.08)$ & $10.63(0.13)$ & $9.20(0.14)$ & $7.70(0.02)$ \\
\hline PROP & $2.63(0.05)$ & $2.92(0.03)$ & $2.91(0.00)$ & $1.97(0.09)$ \\
\hline CAF & $15.26(1.02)$ & $63.10(0.08)$ & $\begin{array}{l}17.45 \\
(0.88)\end{array}$ & $\begin{array}{l}16.96 \\
(0.61)\end{array}$ \\
\hline CBZ & $2.99(0.04)$ & $2.98(0.04)$ & $3.49(0.04)$ & $2.98(0.01)$ \\
\hline $\mathrm{BF}$ & $0.73(0.12)$ & $1.55(0.03)$ & $0.91(0.04)$ & $1.45(0.13)$ \\
\hline
\end{tabular}

Science and Technology of China (No. 2012ZX07313-001-07), and the People Programme (Marie Curie Actions) of the European Union's Seventh Programme FP7/2007-2013 under a REA grant (Agreement No. 318926).

\section{Appendix A. Supplementary data}

Supplementary data associated with this article can be found online at http://dx.doi.org/10.1016/j.jes.2014.06.022.

\section{R E F E R E N C E S}

Batt, A.L., Kostich, M.S., Lazorchak, J.M., 2008. Analysis of ecologically relevant pharmaceuticals in wastewater and surface water using selective solid-phase extraction and UPLC-MS/MS. Anal. Chem. 80 (13), 5021-5030.

Behera, S.K., Kim, H.W., Oh, J.E., Park, H.S., 2011. Occurrence and removal of antibiotics, hormones and several other pharmaceuticals in wastewater treatment plants of the largest industrial city of Korea. Sci. Total Environ. 409 (20), 4351-4360.

Ben, W.W., Qiang, Z.M., Adams, C., Zhang, H.Q., Chen, L.P., 2008. Simultaneous determination of sulfonamides, tetracyclines and tiamulin in swine wastewater by solid-phase extraction and liquid chromatography-mass spectrometry. J. Chromatogr. A 1202 (2), 173-180.

Castiglioni, S., Bagnati, R., Fanelli, R., Pomati, F., Calamari, D., Zuccato, E., 2006. Removal of pharmaceuticals in sewage treatment plants in Italy. Environ. Sci. Technol. 40 (1), 357-363.

Chen, F., Ying, G.G., Kong, L.X., Wang, L., Zhao, J.L., Zhou, L.J., Zhang, L.J., 2011. Distribution and accumulation of endocrine-disrupting chemicals and pharmaceuticals in wastewater irrigated soils in Hebei, China. Environ. Pollut. 159 (6), 1490-1498.

Ding, Y.J., Zhang, W.H., Gu, C., Xagoraraki, I., Li, H., 2011. Determination of pharmaceuticals in biosolids using accelerated solvent extraction and liquid chromatography/ tandem mass spectrometry. J. Chromatogr. A 1218 (1), 10-16.

Gao, L.H., Shi, Y.L., Li, W.H., Niu, H.Y., Liu, J.M., Cai, Y.Q., 2012. Occurrence of antibiotics in eight sewage treatment plants in Beijing, China. Chemosphere 86 (6), 665-671.

Göbel, A., McArdell, C.S., Suter, M.J.F., Giger, W., 2004. Trace determination of macrolide and sulfonamide antimicrobials, a human sulfonamide metabolite, and trimethoprim in wastewater using liquid chromatography coupled to electrospray tandem mass spectrometry. Anal. Chem. 76 (16), 4756-4764.

Gracia-Lor, E., Sancho, J.V., Hernández, F., 2011. Multi-class determination of around 50 pharmaceuticals, including 26 antibiotics, in environmental and wastewater samples by ultra-high performance liquid chromatography-tandem mass spectrometry. J. Chromatogr. A 1218 (16), 2264-2275.

Gros, M., Petrović, M., Barceló, D., 2009. Tracing pharmaceutical residues of different therapeutic classes in environmental waters by using liquid chromatography/quadrupole-linear ion trap mass spectrometry and automated library searching. Anal. Chem. 81 (3), 898-912.

Gulkowska, A., Leung, H.W., So, M.K., Taniyasu, S., Yamashita, N., Yeunq, L.W.Y., Richardson, B.J., Lei, A.P., Giesy, J.P., Lam, P.K.S., 2008. Removal of antibiotics from wastewater by sewage treatment facilities in Hong Kong and Shenzhen, China. Water Res. 42 (1-2), 395-403.

Jia, A., Wan, Y., Xiao, Y., Hu, J.Y., 2012. Occurrence and fate of quinolone and fluoroquinolone antibiotics in a municipal sewage treatment plant. Water Res. 46 (2), 387-394.

Kasprzyk-Hordern, B., Dinsdale, R.M., Guwy, A.J., 2007. Multi-residue method for the determination of basic/neutral pharmaceuticals and illicit drugs in surface water by solid-phase extraction and ultra performance liquid chromatography-positive electrospray ionisation tandem mass spectrometry. J. Chromatogr. A 1161 (1-2), 132-145.

Kasprzyk-Hordern, B., Dinsdale, R.M., Guwy, A.J., 2008. Multiresidue methods for the analysis of pharmaceuticals, personal care products and illicit drugs in surface water and wastewater by solid-phase extraction and ultra performance liquid chromatography-electrospray tandem mass spectrometry. Anal. Bioanal. Chem. 391 (4), 1293-1308.

Kasprzyk-Hordern, B., Dinsdale, R.M., Guwy, A.J., 2009. The removal of pharmaceuticals, personal care products, endocrine disruptors and illicit drugs during wastewater treatment and its impact on the quality of receiving waters. Water Res. 43 (2), 363-380.

Li, B., Zhang, T., 2010. Biodegradation and adsorption of antibiotics in the activated sludge process. Environ. Sci. Technol. 44 (9), 3468-3473.

Li, B., Zhang, T., Xu, Z.Y., Fang, H.H.P., 2009. Rapid analysis of 21 antibiotics of multiple classes in municipal wastewater using 
ultra performance liquid chromatography-tandem mass spectrometry. Anal. Chim. Acta. 645 (1-2), 64-72.

Lillenberg, M., Yurchenko, S., Kipper, K., Herodes, K., Pihl, V., Sepp, K., Lõhmus, R., Nei, L., 2009. Simultaneous determination of fluoroquinolones, sulfonamides and tetracyclines in sewage sludge by pressurized liquid extraction and liquid chromatography electrospray ionization-mass spectrometry. J. Chromatogr. A 1216 (32), 5949-5954.

Lindberg, R.H., Wennberg, P., Johansson, M.I., Tysklind, M., Andersson, B.A.V., 2005. Screening of human antibiotic substances and determination of weekly mass flows in five sewage treatment plants in Sweden. Environ. Sci. Technol. 39 (10), 3421-3429.

Lindsey, M.E., Meyer, M., Thurman, E.M., 2001. Analysis of trace levels of sulfonamide and tetracycline antimicrobials, in groundwater and surface water using solid-phase extraction and liquid chromatography/mass spectrometry. Anal. Chem. 73 (19), 4640-4646.

López-Serna, R., Petrović, M., Barceló, D., 2011. Development of a fast instrumental method for the analysis of pharmaceuticals in environmental and wastewaters based on ultra high performance liquid chromatography (UHPLC)-tandem mass spectrometry (MS/MS). Chemosphere 85 (8), 1390-1399.

Martín, J., Camacho-Muñoz, M.D., Santos, J.L., Aparicio, I., Alonso, E., 2012. Distribution and temporal evolution of pharmaceutically active compounds alongside sewage sludge treatment. Risk assessment of sludge application onto soils. J. Environ. Manag. 102, 18-25.

McArdell, C.S., Molnar, E., Suter, M.J.F., Giger, W., 2003. Occurrence and fate of macrolide antibiotics in wastewater treatment plants and in the Glatt Valley Watershed, Switzerland. Environ. Sci. Technol. 37 (24), 5479-5486.

Miao, X.S., Yang, J.J., Metcalfe, C.D., 2005. Carbamazepine and its metabolites in wastewater and in biosolids in a municipal wastewater treatment plant. Environ. Sci. Technol. 39 (19), 7469-7475.

Nakada, N., Tanishima, T., Shinohara, H., Kiri, K., Takada, H., 2006. Pharmaceutical chemicals and endocrine disrupters in municipal wastewater in Tokyo and their removal during activated sludge treatment. Water Res. 40 (17), 3297-3303.

Narumiya, M., Nakada, N., Yamashita, N., Tanaka, H., 2013. Phase distribution and removal of pharmaceuticals and personal care products during anaerobic sludge digestion. J. Hazard. Mater. 260, 305-312.

Okuda, T., Yamashita, N., Tanaka, H., Matsukawa, H., Tanabe, K., 2009. Development of extraction method of pharmaceuticals and their occurrences found in Japanese wastewater treatment plants. Environ. Int. 35 (5), 815-820.

Pan, X., Qiang, Z.M., Ben, W.W., Chen, M.X., 2011a. Simultaneous determination of three classes of antibiotics in the suspended solids of swine wastewater by ultrasonic extraction, solid-phase extraction and liquid chromatography-mass spectrometry. J. Environ. Sci. 23 (10), 1729-1737.

Pan, X., Qiang, Z.M., Ben, W.W., Chen, M.X., 2011b. Residual veterinary antibiotics in swine manure from concentrated animal feeding operations in Shandong Province, China. Chemosphere 84 (5), 695-700.

Rosal, R., Rodríguez, A., Perdigón-Melón, J.A., Petre, A., García-Calvo, E., Gómez, M.J., Aguera, A., Fernandez-Alba, A.R., 2010. Occurrence of emerging pollutants in urban wastewater and their removal through biological treatment followed by ozonation. Water Res. 44 (2), 578-588.

Sabourin, L., Duenk, P., Bonte-Gelok, S., Payne, M., Lapen, D.R., Topp, E., 2012. Uptake of pharmaceuticals, hormones and parabens into vegetables grown in soil fertilized with municipal biosolids. Sci. Total Environ. 431, 233-236.

Seifrtová, M., Nováková, L., Lino, C., Pena, A., Solich, P., 2009. An overview of analytical methodologies for the determination of antibiotics in environmental waters. Anal. Chim. Acta. 649 (2), 158-179.

Shao, B., Jia, X.F., Wu, Y.N., Hu, J.Y., Tu, X.M., Zhang, J., 2007. Multi-class confirmatory method for analyzing trace levels of tetracyline and quinolone antibiotics in pig tissues by ultra-performance liquid chromatography coupled with tandem mass spectrometry. Rapid Commun. Mass Spectrom. 21 (21), 3487-3496.

Ternes, T., Bonerz, M., Schmidt, T., 2001. Determination of neutral pharmaceuticals in wastewater and rivers by liquid chromatography-electrospray tandem mass spectrometry. J. Chromatogr. A 938 (1-2), 175-185.

Thomas, P.M., Foster, G.D., 2005. Tracking acidic pharmaceuticals, caffeine, and triclosan through the wastewater treatment process. Environ. Toxicol. Chem. 24 (1), 25-30.

US EPA, 2007. Method 1694: Pharmaceuticals and Personal Care Products in Water, Soil, Sediment, and Biosolids by HPLC/MS/ MS (Washington, D.C., EPA-821-R-08-002).

Vieno, N., Tuhkanen, T., Kronberg, L., 2007. Elimination of pharmaceuticals in sewage treatment plants in Finland. Water Res. 41 (5), 1001-1012.

Wang, C.A., Shi, H.L., Adams, C.D., Gamagedara, S., Stayton, I., Timmons, T., Ma, Y.F., 2011. Investigation of pharmaceuticals in Missouri natural and drinking water using high performance liquid chromatography-tandem mass spectrometry. Water Res. 45 (4), 1818-1828.

Wilson, S.C., Alcock, R.E., Sewart, A.P., Jones, K.C., 1997. Persistence of organic contaminants in sewage sludge-amended soil: a field experiment. J. Environ. Qual. 26 (6), 1467-1477.

Wu, C.X., Spongberg, A.L., Witter, J.D., 2008. Determination of the persistence of pharmaceuticals in biosolids using liquid-chromatography tandem mass spectrometry. Chemosphere 73 (4), 511-518.

Wu, X.Q., Conkle, J.L., Gan, J., 2012. Multi-residue determination of pharmaceutical and personal care products in vegetables. J. Chromatogr. A 1254, 78-86.

Xu, W.H., Zhang, G., Li, X.D., Zou, S.C., Li, P., Hu, Z.H., Li, J., 2007. Occurrence and elimination of antibiotics at four sewage treatment plants in the Pearl River Delta (PRD), South China. Water Res. 41 (19), 4526-4534.

Xue, W.C., Wu, C.Y., Xiao, K., Huang, X., Zhou, H.D., Tsuno, H., Tanaka, H., 2010. Elimination and fate of selected micro-organic pollutants in a full-scale anaerobic/anoxic/ aerobic process combined with membrane bioreactor for municipal wastewater reclamation. Water Res. 44 (20), 5999-6010.

Yang, J.F., Ying, G.G., Zhao, J.L., Tao, R., Su, H.C., Chen, F., 2010. Simultaneous determination of four classes of antibiotics in sediments of the Pearl Rivers using RRLC-MS/MS. Sci. Total Environ. 408 (16), 3424-3432.

Ye, Z.Q., Weinberg, H.S., Meyer, M.T., 2007. Trace analysis of trimethoprim and sulfonamide, macrolide, quinolone, and tetracycline antibiotics in chlorinated drinking water using liquid chromatography electrospray tandem mass spectrometry. Anal. Chem. 79 (3), 1135-1144. 